\title{
CONTROLANDO O INCONTROLÁVEL: A APLICAÇÃO DAS REGRAS DE ATENDIMENTO NA CONSTRUÇÃO DA COMPREENSÃO MÚTUA ENTRE CLIENTES E ATENDENTES EM UM CALL CENTER ${ }^{*}$
}

\author{
Joseane de Souza* \\ Ana Cristina Ostermann ${ }^{* \star *}$ \\ Universidade do Vale do Rio dos Sinos \\ São Leopoldo, RS, Brasil \\ Maria de Lourdes Borges ${ }^{\star \star \star \star}$ \\ Centro Universitário La Salle \\ Canoas, RS, Brasil
}

\begin{abstract}
Resumo: Este artigo propõe analisar a compreensão mútua como faceta dos comportamentos diádicos em um encontro de serviço, elemento discursivo pouco estudado, conforme a literatura de marketing e gestão de pessoas aponta (MA; DUBÉ, 2011). Especificamente, investiga-se como a compreensão mútua é ou não construída entre clientes e atendentes de um serviço telefônico a partir da aplicação dos scripts e regras de atendimento (elemento textual) criadas pela gestão de pessoas. Utilizando a Análise da Conversa (SACKS; SCHEGLOFF; JEFFERSON, 1974), analisam-se dados reais de interações de maneira microetnográfica. O corpus deste artigo constitui-se de 126 interações gravadas em áudio na central de atendimento do Disque Saúde em Brasília. Os resultados revelam que somente o seguimento das regras não garante o estabelecimento da compreensão mútua, ao contrário, deixa margem para ações interacionais distintas, como o abandono da compreensão mútua quando os atendentes deparam-se com demandas da interação que não podem ser previstas pelo script.
\end{abstract}

Palavras-chave: Análise da Conversa. Helplines. Interação ao telefone. Prescrições. Humanização.

1 INTRODUÇÃO

É possível controlar as interações e os discursos durante encontros de prestação de serviços por meio de textos / scripts? Embora a natureza interativa dos encontros de

\footnotetext{
* Agradecemos à CAPES pelo apoio por meio de bolsas de mestrado e doutorado concedidas à primeira autora; ao CNPq e à FAPERGS pelo apoio obtido por meio de Bolsa de Produtividade (Processo CNPq $\mathrm{n}^{\circ}$ 311473/2012-1) e auxílios à pesquisa obtidos através dos editais FAPERGS PqG n 02/2011 (Processo n ${ }^{\circ}$ 11/1605-0), CNPq Chamada MCTI/CNPq/SPM-PR/MDA n ${ }^{\circ}$ 32/2012 (Processo n ${ }^{\circ}$ 405154/2012-7), concedidos à segunda autora; e auxílios à pesquisa obtidos através do edital FAPERGS ARD n ${ }^{\circ} 03 / 2012$ (Processo $\left.n^{\mathrm{o}} 12 / 1270-4\right)$, concedido à terceira autora.

** Doutoranda em Linguística Aplicada. Bolsista CAPES. Email: joseanedesouza@terra.com.br.

*** Doutora em Linguística. Professora Titular em Linguística Aplicada. Email: aco@unisinos.br.

**** Doutora em Administração. Professora Colaboradora. Email: maluborg@gmail.com.
} 
prestação de serviço tenha sido enfatizada pelos pesquisadores de marketing, há uma problemática pouco estudada a respeito de como as interações se constituem em um encontro de serviço (MA; DUBÉ, 2011). Este artigo propõe analisar interações entre cliente e provedor de um serviço telefônico prestando particular atenção à compreensão mútua enquanto parte constituinte fundamental em interações de qualquer natureza, mas aqui circunscrita a encontros de serviço, especialmente quando há scripts envolvidos que são privilegiados em detrimento da compreensão mútua. Faz-se refletir também sobre o papel da gestão de pessoas nas organizações, sejam públicas ou privadas, chamando atenção para o que pode ser visto e, por consequência, realizado, ao se voltar o olhar para a linguagem de uma forma mais detida.

A compreensão mútua é aqui entendida a partir da abordagem teóricometodológica da Análise da Conversa, também conhecida como AC (SACKS; SCHEGLOFF; JEFFERSON, 1974). Para a AC, a compreensão mútua é condição sine qua non para que duas ou mais pessoas consigam desenvolver uma interação. Segundo a literatura de marketing em Administração, as interações face a face entre cliente e provedor em contextos de prestação de serviços são caracterizadas como um encontro diádico (SOLOMON et al., 1985), e, assim como em todas as interações profissionais, as pessoas envolvidas precisam compreender-se para que o objetivo do serviço seja alcançado e, preferencialmente, com qualidade. Já Meuter et al. (2000) entendem que o encontro de serviços abrange outras formas de interação, que não a face a face, tais como os serviços prestados por telefone.

Os dados que constituem o corpus deste $\operatorname{artigo~}^{1}$ são 126 interações telefônicas gravadas em áudio na central de atendimento do Disque Saúde em Brasília. O Disque Saúde é um serviço de atendimento telefônico gratuito do Ministério da Saúde que objetiva sanar dúvidas da população relativas a questões de saúde pública, como formas de transmissão e prevenção de doenças, endereços de postos de saúde do SUS etc., e registrar demandas que não estejam sendo atendidas pelo SUS, bem como queixas, o que caracteriza essa linha telefônica como um helpline.

Baker, Emmison e Firth (2005) definem helplines como "serviços de atendimento telefônico que oferecem ajuda, conselho ou apoio em uma ampla gama de áreas, mais comumente nas áreas da saúde e medicina [...] realizado na forma de conversa" (p. 1, tradução nossa). Geralmente o atendimento inicia com a descrição do problema pelo(a) usuário(a).

Serviços de atendimento telefônico do tipo helpline normalmente são gratuitos. São exemplos no Brasil o 190 da Brigada Militar, os bombeiros, o SAMU (Serviço de Atendimento Móvel de Urgência), entre outros. Nessas helplines, além de o atendimento não dispor do contato visual da interação face a face, ele é guiado por regras de atendimento contidas nos scripts. Os scripts são formados por um conjunto de prescrições que objetivam orientar o atendente para o que ele deve fazer na prestação do serviço, e que acabam refletindo a cultura da organização.

\footnotetext{
${ }^{1} \mathrm{O}$ presente estudo faz parte de uma pesquisa maior, coordenada pela segunda autora, iniciada em 2006. Tal pesquisa deu origem a comunicações orais e outra publicação na qual se investigou a dificuldade na aplicação dos scripts pelos atendentes (OSTERMANN; SOUZA, 2011) com a utilização desse mesmo corpus de 126 interações.
} 
Um dos livros que influenciou a gestão na elaboração do script do Disque Saúde foi o Como encantar o cliente pelo telefone (ANDERSON, 1995). O texto sugere, entre outras coisas, que sejam realizadas perguntas de sondagem e de confirmação durante um atendimento telefônico que pretenda dar conta do "encantamento" do cliente. Faz sentido que um serviço de atendimento telefônico que busca solucionar as mais variadas dúvidas da população, tal como o Disque Saúde, busque organizar o atendimento telefônico. Sob esse ponto de vista, pode-se entender que há uma tentativa de controlar a conversa para fins de atingir de maneira eficaz a satisfação - ou o "encantamento" - do cliente. Portanto, o conteúdo e a aplicação do livro no contexto do Disque Saúde faz emergir a relação entre texto e discurso. Clifton (2012, p. 160) acredita que as organizações não possuem uma existência pré-discursiva, uma vez que o significado atribuído ao presente, passado e futuro dos eventos (tais como um atendimento de call center) é criado discursivamente por meio da negociação situada dos significados.

Ocorre que, na prática, os atendentes deparam-se com questões das mais variadas, muitas vezes envolvendo assuntos delicados, em que os textos e os scripts não mais os auxiliam, já que não podem prever tais situações. Cria-se então uma ligação telefônica mecânica, fria e sem engajamento na conversa por parte dos teleatendentes (SILVA et al., 2002), resultando na baixa qualidade do serviço. Nesse modo de operar, a visão de "texto" é a de um elemento que pode assegurar qualidade, já que padronizaria as falas. Entretanto, por mais que um texto seja desenhado para um interlocutor específico, ele ainda é mais estanque que uma fala espontânea, justamente por não poder ajustar por completo a fala ao interlocutor, no momento mesmo em que ela é produzida, conforme o que se percebe do outro, o que, felizmente, pode-se fazer por meio da fala.

Estudos realizados nas áreas de Análise do Discurso, de Sociolinguística Interacional e de Análise da Conversa demonstram que a padronização demasiada da fala produz vários resultados que vão contra aquilo que as organizações realmente almejam (OLIVEIRA, 2009; SILVA et al., 2002). Ou seja, o dito "atendimento", na maioria das vezes bastante planejado a priori e completamente descolado da interação propriamente dita, não engloba o fator essencial para que as ligações sejam "bemsucedidas": o entendimento daquilo que o cliente está dizendo ou querendo.

Portanto, para atingir o objetivo do artigo de fazer refletir sobre a compreensão mútua como essencial nas interações, atrelada diretamente a características na aplicação das regras de atendimento, inicialmente apresenta-se o referencial teórico sobre a comunicação na área da gestão e a visão de alguns estudos interacionais. Em seguida, trata-se da metodologia utilizada neste artigo, e passa-se à análise dos dados. Por fim, discutem-se as implicações da análise e do entendimento das práticas dos atendentes para as áreas em que a linguagem e a intersubjetividade sejam o meio para a realização do trabalho. 
O que está por trás das práticas que não favorecem o entendimento mútuo em um encontro de serviço pode ser o entendimento dos gestores sobre a natureza da comunicação, que pode se traduzir pela "metáfora do conduto". A "metáfora do conduto", segundo Reddy (2000), refere-se ao entendimento de que "comunicar" seria o mesmo que "transmitir"; as palavras ou expressões estariam carregadas de um significado fixo e independente de contexto, que traduziriam exatamente as ideias que um indivíduo (A) deseja transmitir, e, assim, seriam transportadas intactas ao outro, o receptor (B), por um “duto condutor”, no momento da comunicação.

Essa concepção está arraigada em uma visão de interação que não reflete sobre o elemento principal da comunicação: a compreensão mútua. Na verdade, é na construção de um entendimento comum entre os falantes que ocorre a interação, de maneira impossível de ser antecipadamente controlada. Em contrapartida, a fala mecanizada ou "scriptada" provém de uma percepção de interação como o mero envio e recepção de mensagens "prontas", como na metáfora do conduto. Nesse sentido, entende-se que o dilema de como prestar um serviço eficiente e padronizado em um nível aceitável de qualidade e, ao mesmo tempo, considerar cada cliente como uma pessoa única persiste nos estudos sobre serviços (MA; DUBÉ, 2011).

Para a compreensão dessa problemática, existem contribuições importantes provenientes da Linguística Aplicada, destacando-se a abordagem teórico-metodológica da Análise da Conversa (AC), vista mais adiante. Ostermann, Andrade e Silva (2013) explicam que, apesar de oriunda da Sociologia, no Brasil a AC possui pesquisadores frequentemente alocados em departamentos de estudos de linguagem, de Linguística Aplicada ou mesmo de Linguística. As autoras lembram ainda que, enquanto a Linguística Aplicada preocupa-se essencialmente com a linguagem, a AC ocupa-se da investigação da conduta social, e a partir daí surgem possibilidades para se chamar a atenção dos atores sociais para as práticas de linguagem nos diferentes contextos. Antes de tratarmos um pouco mais da AC, faz-se importante saber o que os estudos interacionais sobre atendimento, ou encontro de serviços, observaram até agora.

\subsection{O ATENDIMENTO A PARTIR DO PONTO DE VISTA DOS ESTUDOS INTERACIONAIS}

Alguns estudos têm focalizado as estratégias de comunicação entre atendentes e usuários de serviços no Brasil e no exterior. Oliveira (2013) apresenta um panorama geral de leituras essenciais, textos clássicos e estudos recentes que tratam da Linguística Aplicada aos contextos empresariais e mostram que há uma preocupação dos estudos discursivo-interacionais em ampliar seus horizontes para chegar às organizações brasileiras, sejam elas públicas ou privadas. Essa preocupação corresponde à importância do olhar sobre a atividade interacional, atividade presente em praticamente todas as funções organizacionais, que cada vez mais utiliza novas tecnologias, e que, no entanto, em sua maior parte, não consegue alcançar um patamar estável de resolução. Isso porque está focada em uma cultura empresarial que, na essência, estrutura-se sob 
uma abordagem funcionalista em que a produtividade acaba sendo medida em números, e não de forma qualitativa e específica.

Da mesma maneira, geralmente os modelos de gestão de recursos humanos nas organizações baseiam-se em planejamentos rígidos, principalmente quando o assunto é a gestão de pessoas em call centers. Salienta-se que, contraditoriamente, há nos estudos organizacionais uma tendência, ainda que tímida, à compreensão das organizações como processos dinâmicos resultantes das ações de seus membros (WEICK, 1995).

Dessa maneira, somente com a atenção voltada ao que acontece microestruturalmente nas organizações será possível compreender se um modelo de gestão funciona para o propósito de prestação de determinado serviço. Assim, deter-se no que acontece nas práticas de linguagem é uma das formas que mais rapidamente pode mostrar o que ocorre em uma organização, aspecto esse já reverberado também por pesquisadores da área da Administração, como Weick (1995) e Hepburn e Potter (2007). Conforme afirma Oliveira (2009), a partir do momento em que funcionários e direção são estimulados a refletir sobre o papel da linguagem ao se desenvolver uma cultura de integração e inovação, cada indivíduo também está sendo convocado a reconhecer o seu próprio poder na construção da empresa e do mundo em que querem viver.

Com base nessas reflexões, passa-se à explicação da Análise da Conversa tanto com suas implicações teóricas e de aplicação como com seu método de investigação dos encontros de serviço, aqui especificamente as interações em helplines.

\section{METODOLOGIA: A ABORDAGEM DA ANÁLISE DA CONVERSA, A COMPREENSÃO MÚTUA E A CONTRIBUIÇÃO PARA A ÁREA DA GESTÃO NAS ORGANIZAÇÕES}

A Análise da Conversa é uma abordagem qualitativa que visa a investigar a estrutura da interação na qual as pessoas estão engajadas, e como cada parte atua na construção dessa interação. Como as pessoas agem na sequencialidade da interação é o que nos interessa, isto é, como um enunciado de um participante é entendido pelo outro, e assim sucessivamente. Nessa abordagem, estuda-se a fala das pessoas - não seus pensamentos, intenções, crenças ou experiências de vida, que estão subentendidos na fala, ou seja, podem ser expressos por meio dela (OSTERMANN, 2012). Conforme explica Ostermann (2012), a perspectiva da Análise da Conversa vê a fala como uma forma de ação social - isto é, como uma forma de fazer coisas no mundo.

Como a utilização da Análise da Conversa nos estudos organizacionais não é trivial (LLEWELLYN; HINDMARSCH, 2010), explicitam-se os três estágios necessários para a concretização da estratégia metodológica deste trabalho: coleta de dados, transcrição dos dados e análise.

A coleta de dados envolveu a gravação das interações entre atendentes do Disque Saúde, do Ministério da Saúde, e usuárias desse serviço durante as ligações ocorridas em oito dias de trabalho no mês de julho de $2007^{2}$. As gravações foram realizadas como de costume pelos atendentes e depois recuperadas em CD entregue em mãos à primeira autora na ocasião da coleta de dados pelo setor de tecnologia da instituição.

\footnotetext{
${ }^{2}$ Utilizam-se ligações para o Disque Saúde da Mulher, um submenu do Disque Saúde.
} 
Na ocasião da coleta, houve dez dias de observação do trabalho na central do Disque Saúde que renderam dados de diário de campo, também utilizados em abordagens de Análise da Conversa e Etnometodologia como esta. Entrevista informal com a supervisora da época também está organizada como dado de diário de campo.

Além disso, como se pode observar, as interações que constituem nosso corpus foram conversas que ocorreram naturalmente, portanto sem a interferência da pesquisadora que coletou os dados. Esses dados tornam-se, assim, adequados para serem submetidos a tal análise, uma vez que mostram os procedimentos, métodos, organização e recursos que os interagentes utilizaram para fazer sentido da fala um do outro (HUTCHBY; WOOFFITT, 1998).

Os atendentes envolvidos na pesquisa assinaram um Termo de Consentimento Livre e Esclarecido (TCLE), e as usuárias do serviço sabiam de antemão que suas ligações poderiam ser gravadas pela instituição, em função de uma mensagem existente no menu principal. $\mathrm{O}$ acesso aos dados foi realizado respeitando os princípios éticos que regulam pesquisas envolvendo seres humanos ${ }^{3}$.

O segundo estágio dessa abordagem é a transcrição dos dados gravados. A transcrição é vista como uma representação dos dados (HUTCHBY; WOOFFITT, 1998), que reflete não somente o conteúdo, mas também a forma como o evento ocorreu. Observe-se o Quadro 1, que esclarece as convenções utilizadas nos excertos que serão apresentados ${ }^{4}$.

\section{Quadro 1 - Convenções de transcrição}

\begin{tabular}{|cc|}
\hline [texto] & Falas sobrepostas \\
\hline$(1.8)$ & Pausa \\
\hline, & Entonação contínua \\
\hline$\cdot$ & Entonação descendente \\
\hline$?$ & Entonação ascendente \\
\hline$:$ & Alongamento de som \\
\hline TEXTo & Fala com volume mais alto \\
\hline Texto & Sílaba, palavra ou som acentuado \\
\hline (texto) & Dúvida na transcrição \\
\hline XXXX & Texto inaudível \\
\hline$(($ texto) $)$ & Comentários da transcritora \\
\hline @@@ & Risada \\
\hline${ }^{\circ}$ texto ${ }^{\circ}$ & Fala em volume mais baixo \\
\hline
\end{tabular}

\footnotetext{
${ }^{3}$ Termos de consentimento em consonância com o Projeto $n^{\circ}$ 05/043, homologado pelo Comitê de Ética da Unisinos em 11 de novembro de 2005.

4 As convenções de transcrição utilizadas foram adaptadas pelo grupo de pesquisa coordenado pela segunda autora, registrado e ativo no Diretório de Grupos de Pesquisa do CNPq.
} 
$\mathrm{O}$ terceiro estágio refere-se à análise dos dados propriamente dita. Conforme Drew e Heritage (1992, p. 53), a AC "oferece uma perspectiva especialmente forte e coerente sob a qual se pode investigar as atividades que constituem a vida das instituições sociais.”. Tendo em mente os padrões e os mecanismos da conversa cotidiana, que podem ser facilmente observados por todos os falantes de determinada língua, o analista consegue descrever práticas e ações próprias da conversa institucional, em seus mais variados contextos.

A compreensão mútua, tema central deste artigo, talvez seja a característica da conversa humana melhor acessada pela AC. O entendimento entre as pessoas e a avaliação que um faz da fala do outro e da conversa em si está disponível na própria fala, a cada turno de cada falante, que leva em consideração o turno anterior do outro. Dessa forma, pela AC é possível saber praticamente todas as ações que estão sendo construídas pelos falantes em dada conversa. Essas ações são indicializadas por práticas conversacionais que são, em sua maioria, cultural e socialmente compartilhadas.

Recentemente, os estudos organizacionais têm feito uma utilização crescente da AC como metodologia em suas investigações (JUNG LAU; OSTERMANN, 2005; SAMRA-FREDERICKS, 2010; OSTERMANN; SOUZA, 2011; CLIFTON, 2009, 2012; LLEWELLYN; HINDMARSCH, 2010; BORGES; OSTERMANN, 2013). Essa utilização torna possíveis avanços de três ordens nos estudos organizacionais. $O$ primeiro avanço refere-se à utilização de uma abordagem metodológica inovadora nos estudos organizacionais (LLEWELLYN; HINDMARSCH, 2010), que vem a suprir uma lacuna apontada pelos próprios estudiosos. O segundo refere-se à possibilidade de uma leitura ativa das ações dos profissionais enquanto realizam seu trabalho (CLIFTON, 2009). O terceiro, por sua vez, reside no potencial analítico da AC, por meio da transposição da abordagem de "o que é dito" para "como é dito", através do desvelamento dos aspectos intersubjetivos presentes nas falas-em-interação (OSTERMANN, 2012).

Além disso, o argumento a respeito da utilização da $\mathrm{AC}$ voltada para a compreensão de um encontro diádico vai além da noção de interdependência diádica estudada anteriormente nos estudos organizacionais (MA; DUBÉ, 2011; SOLOMON et al., 1985). A AC vai além pela possibilidade de mostrar os meios pelos quais as pessoas chegam à compreensão mútua, e não somente assumir a interdependência dos falantes para um encontro diádico ser bem-sucedido, tal como analisam Ma e Dubé (2011).

No presente artigo, após minuciosas observações e análise de 126 ligações, descrevem-se as práticas e ações de duas interações para poder tornar visíveis ao leitor como as características da aplicação dos scripts pelos atendentes refletem a importância da compreensão mútua entre os falantes em questão. Essas interações mostram também a contradição que existe entre as normas e prescrições oriundas da estratégia organizacional e a prática dos atendentes do Disque Saúde. ${ }^{5}$

\footnotetext{
${ }^{5}$ Salienta-se que as duas interações escolhidas são as mais representativas, ou seja, exemplos exemplares de cada um dos dois tipos de práticas recorrentes ao longo da análise das 126 ligações. 
O Disque Saúde está fisicamente localizado junto à Ouvidoria do SUS. Quando foi realizada a coleta de dados do presente estudo (em 2007), havia 176 atendentes, 16 monitores e duas supervisoras ocupando-se do trabalho dos atendimentos. Nesse mesmo espaço físico, atendentes - estudantes dos cursos de graduação na área da saúde revezam-se em dois turnos de seis horas cada, de segunda a sexta-feira. Para começar a trabalhar ali, todos passam por um treinamento de aproximadamente três semanas, realizado a cada contratação, semestralmente, com os novos atendentes. ${ }^{6}$

As pessoas que buscam o serviço do Disque Saúde, nas interações que foram coletadas, pertencentes ao submenu Disque Saúde da Mulher, são mulheres brasileiras com dúvidas relacionadas à saúde física e sexual. Como na maioria das vezes tais dúvidas requerem um diagnóstico médico, acredita-se que o Disque Saúde muitas vezes constitui-se em uma alternativa às filas de espera dos hospitais públicos e dos postos de saúde.

Além de seguirem regras de atendimento específicas, os atendentes devem também consultar um banco de dados pela tela do computador para responder às solicitações das usuárias sobre problemas de saúde e formas de prevenção e prover tais respostas de acordo com o conteúdo ali registrado. Como consequência, muitas vezes o conteúdo pesquisado no banco de dados acaba sendo lido às usuárias. Os atendentes são frequentemente avaliados pelos monitores e por vezes pelas supervisoras por meio do sistema de escuta das ligações. Por esse mesmo sistema, os atendentes podem pedir ajuda dos monitores se dúvidas surgem durante o atendimento.

Analisa-se um momento ${ }^{7}$ da interação nas ligações para o Disque Saúde nomeado pela instituição como "captação da necessidade do cidadão" (nosso grifo), que é referido no roteiro de atendimento como: "fazer perguntas de sondagem e confirmação para captar a necessidade do cidadão". Entende-se que, para o atendente, esse script tem o papel de verificar se ele entendeu corretamente o que a usuária deseja saber, ou qual a sua dúvida (o motivo da ligação propriamente dito), e o ponto exato de onde partir com a explicação. Assim, a orientação do roteiro é a de que o atendente realize perguntas que confirmem o seu entendimento da demanda da usuária e sondem o nível de conhecimento sobre o assunto que a usuária já possui.

Porém, em termos interacionais, observa-se que a realização desse script pelo atendente está ligada à necessidade na ocasião do atendimento. Se para o atendente não houve problemas em entender a demanda da usuária, e se a usuária deixou claro não ter conhecimento prévio sobre o assunto, por que esse script haveria de ser colocado em prática? Em outras palavras, por que o atendente precisaria fazer perguntas de confirmação e de sondagem? Comparem-se às interações mundanas cotidianas, ou até

\footnotetext{
${ }^{6}$ Uma vez que os atendentes não possuem formação médica, não estão autorizados pela instituição a diagnosticar doenças ou realizar avaliações prognósticas aos usuários.

${ }^{7}$ Os momentos de um atendimento do Disque Saúde, conforme os termos encontrados no roteiro de atendimento, são, nesta ordem: 1) "recepção da ligação", quando acontece a saudação institucional; 2) "captação da mensagem", onde se sugere que sejam feitas as perguntas de confirmação e sondagem para "captar a necessidade do cidadão"; 3) "pesquisa" que o atendente realiza sobre o assunto solicitado pelo cidadão; 4) "resposta", momento em que os atendentes são encorajados a incluírem informações sobre prevenção de doenças; e 5) "encerramento da ligação", com uma frase institucional padronizada.
} 
mesmo às interações em alguns contextos institucionais: por que seriam feitas perguntas se não há uma necessidade, ou se as respostas já são sabidas? ${ }^{8}$ Nesta análise, poderão ser vistas as diferentes maneiras de os atendentes lidarem com esse mesmo script, reveladas por diferentes práticas encontradas nos dados. A seguir são apresentados excertos que representam as duas práticas. Conforme explicado na introdução, adota-se o termo "usuária" para referência às mulheres que buscam o serviço.

\subsection{PERGUNTAS DE AFUNILAMENTO}

O autor que pesquisara ligações de emergência para o 911 nos Estados Unidos (ZIMMERMAN, 1984) observou um tipo de série de turnos de fala nas interações e o nomeou como "série de interrogações" (1984, p. 211, nossa tradução), explicando que ele é visto normalmente como uma sequência dentro do par de enunciados solicitação do usuário - resposta do atendente. Em atendimento à prescrição institucional da realização das perguntas de confirmação e de sondagem, em um primeiro momento observou-se que os atendentes utilizam-se dessa prática na busca pelo entendimento da solicitação da usuária. Eles fazem perguntas com vistas a especificar o problema ou solicitação até o ponto em que se torna possível prover a informação de fato. Nesta análise, essa sequência será chamada de perguntas de afunilamento.

Nos excertos que serão reproduzidos a partir deste ponto, podemos observar essa prática $^{9}$. A usuária inicia com o relato de seu problema de irregularidade menstrual, menciona o uso da pílula, em seguida a atendente vai construindo um entendimento comum sobre o que acontecera com a usuária até o momento da ligação.

\section{INTERAÇÃO A [DISK190707SALETE]}

\section{Excerto A1}

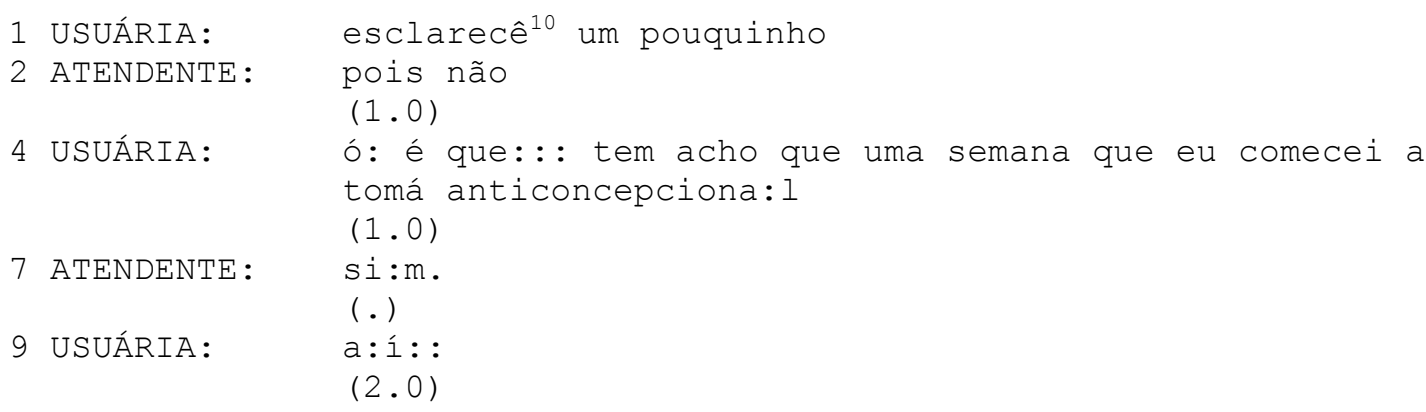

\footnotetext{
${ }^{8}$ Acredita-se que a necessidade de o atendente comprovar para monitores e supervisores determinados aspectos desse atendimento mina a intersubjetividade entre atendente e usuária, pois o atendente precisa, ao mesmo tempo em que interage, refletir sobre a interação, atentando para cobranças futuras sobre seu trabalho, como o porquê da não realização de um script.

${ }^{9}$ Nessa gravação, a saudação institucional ficou cortada.

${ }^{10}$ A grafia não padrão nas transcrições segue o raciocínio de que, quando audíveis, os fonemas são representados; quando não audíveis, não são representados (como é o caso do "r" no infinitivo dos verbos). Quando audíveis, normalmente sinalizam uma mudança de atividade no evento discursivo; e.g. passar de uma sequência de perguntas e respostas à leitura do script.
} 


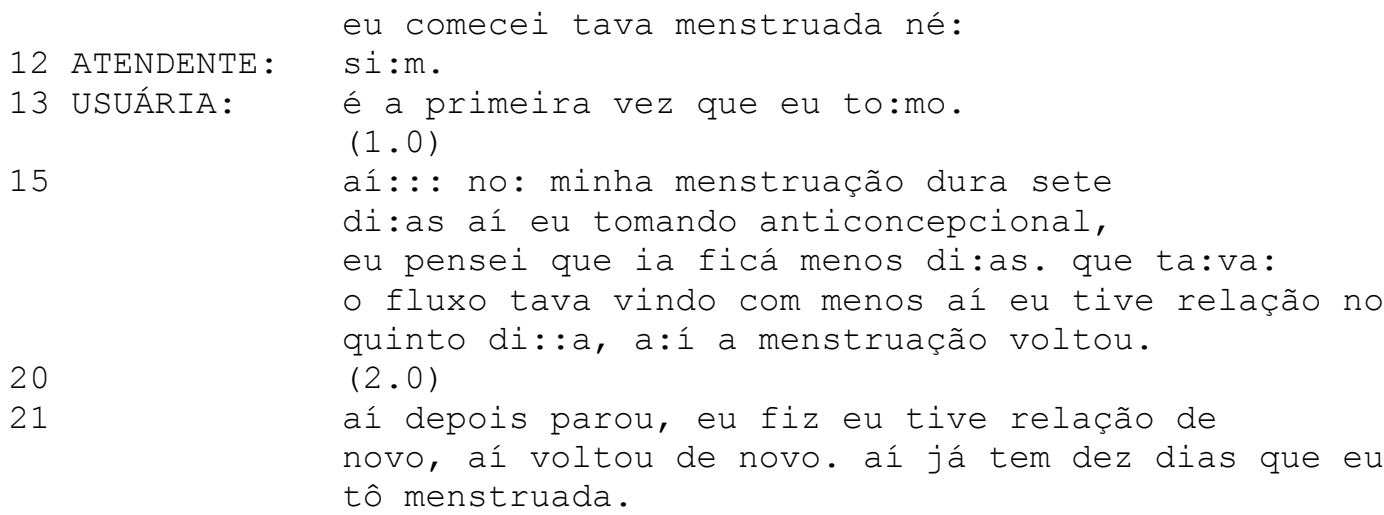

O excerto A1 mostra o momento inicial no qual geralmente os usuários buscam esclarecer o motivo da ligação. Nesse segmento inicial, na linha 1, a usuária provê uma razão parcial para a ligação ao dizer "esclarecê um pouquinho" - parcial porque ela não antecipa sobre o que se trata, e na linha 2 a atendente acena positivamente para que a usuária prossiga. A usuária relata um fato das linhas 4 a 23 , e novos acenos para que prossiga são realizados pela atendente nas linhas 7 e 12 . Note-se que esse relato age para esclarecer a razão de sua ligação para o Disque Saúde, mas neste caso parcialmente, pois, em vez de fazer uma pergunta direta sobre o que gostaria de saber, a usuária relata um problema. Assim, a usuária depende de a atendente entender qual é sua demanda.

Nota-se nessa interação que o que dá andamento às perguntas de afunilamento da atendente é que ela está buscando entender qual é exatamente a solicitação da usuária. Observam-se os esforços interacionais da atendente para que a demanda possa ser entendida e, então, atendida (em negrito no Excerto A2):

\section{Excerto A2}

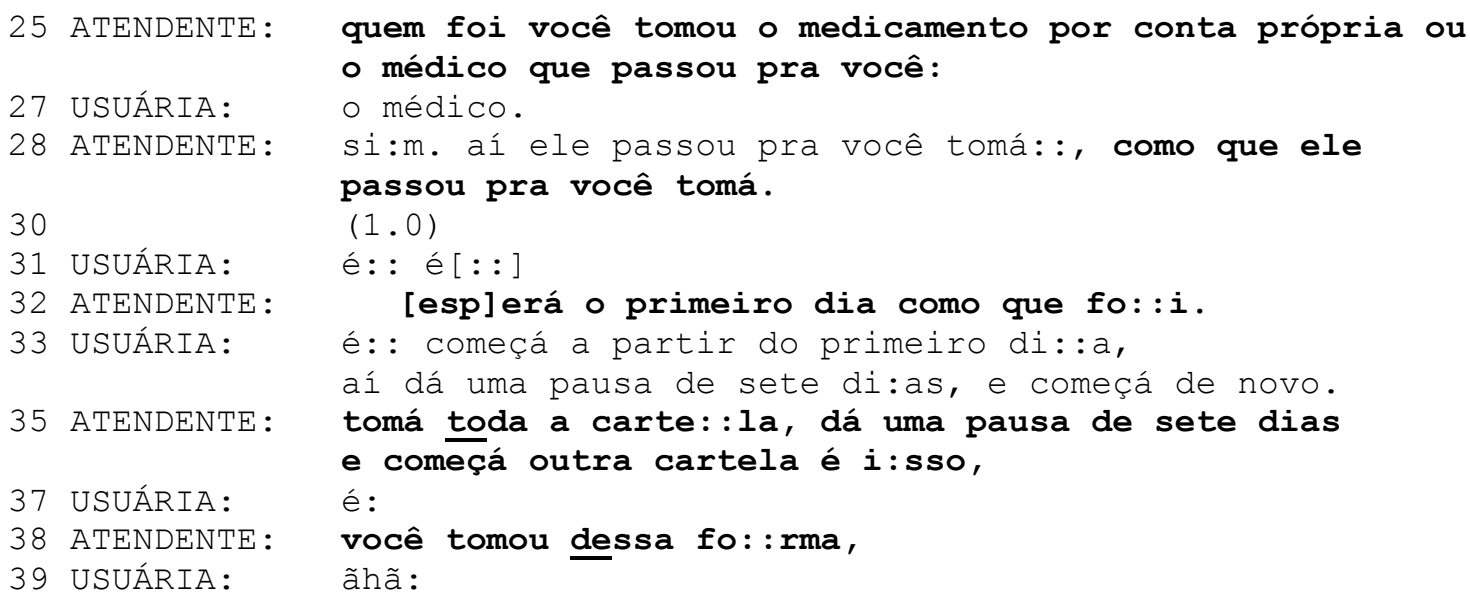

38 ATENDENTE: você tomou dessa fo: :rma,

39 USUÁRIA: ãhã :

Nas linhas 25-26, a atendente realiza uma pergunta de afunilamento ao querer saber quem prescreveu o medicamento em questão. A usuária, ao responder, escolhe uma das alternativas sugeridas na pergunta da atendente. Na sequência, linhas 28-29, 32, 35-36 e 38, a atendente questiona a usuária sobre o modo como ela entendeu que 
deveria tomar a pílula, o que ela parece fazer para descartar a possibilidade de que a usuária não esteja tomando a pílula corretamente. A atendente parece entender $o$ problema implícito no relato (irregularidade menstrual com o uso da pílula anticoncepcional), mas ainda não entendeu especificamente a demanda, a dúvida da usuária. Observe-se o Excerto A3:

\section{Excerto A3}

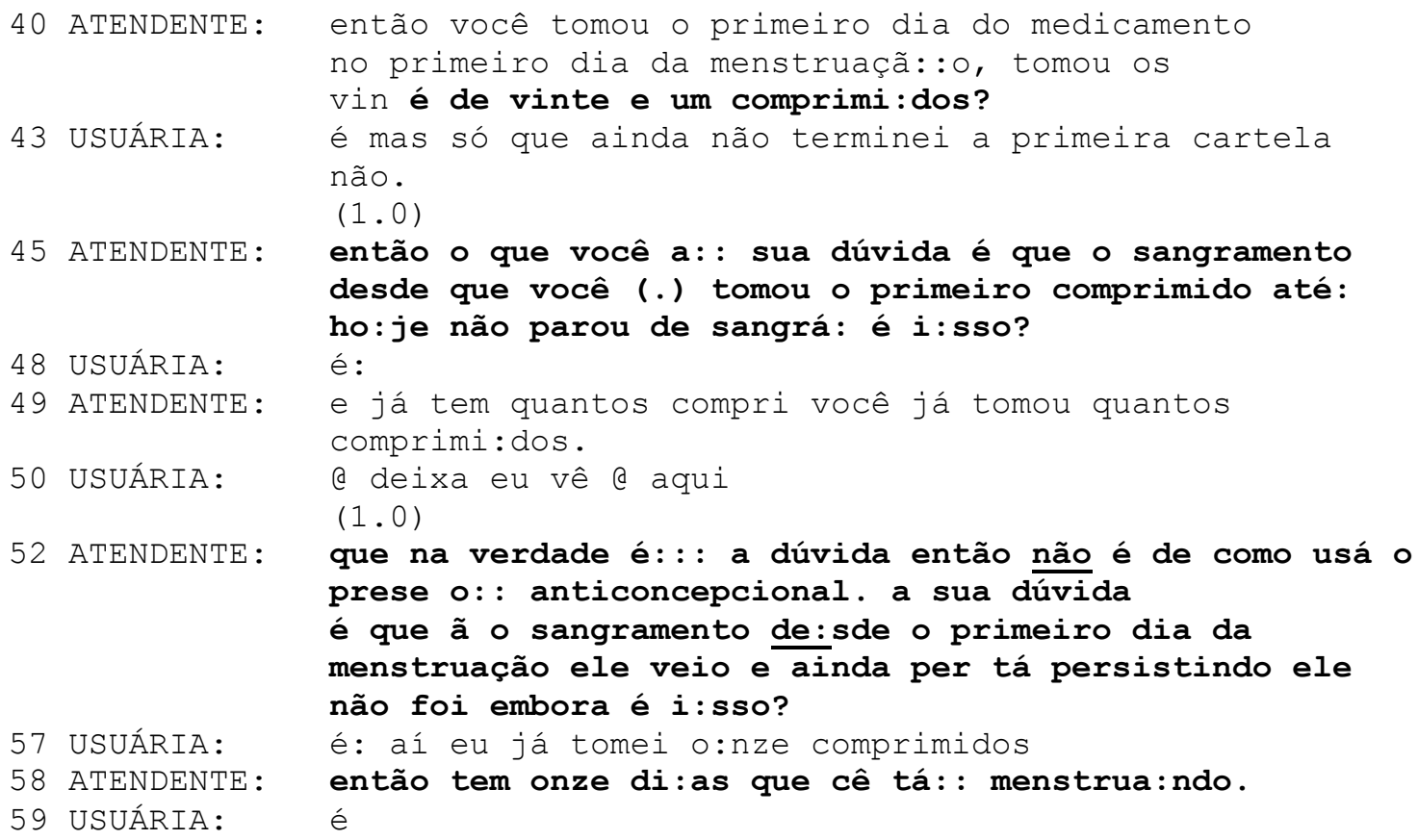

Note-se que a atendente continua realizando perguntas à usuária. Em uma forma mais mecânica e fria de teleatendimento, a atendente poderia ter dito à usuária que não entendeu o que ela quer saber, requisitando uma reformulação mais explícita de sua demanda. Contudo, ao invés disso, ela realiza várias perguntas que agem para entender a demanda da usuária e, além disso, especificar o seu caso ao requerer mais informações, como a pergunta da linha 42, sobre o tipo de pílula que a usuária utiliza. Nas linhas 45-47, a atendente formula o que ela entende ser a demanda da usuária e realiza uma checagem de entendimento mais explícita ao adicionar "é isso?". Nota-se que a usuária confirma o entendimento da atendente na linha 48. Na linha 49, outra pergunta, agora pedindo mais informações para a usuária, e, a partir da linha 52, a atendente repete a formulação que fizera sobre a demanda da usuária, desta vez de uma forma mais completa.

Vale explicar que uma formulação é uma forma explícita de um falante expressar o seu entendimento do que o outro falou, para que este então possa, na sua fala seguinte, confirmar ou desconfirmar tal entendimento (OSTERMANN; SILVA, 2009). Portanto, a formulação é uma estratégia interacional altamente eficaz para um falante se assegurar de que seu entendimento até ali está correto. Essa reapresentação de seu entendimento para uma nova checagem pela usuária (linha 52) demonstra que a atendente está engajada em conseguir entender de fato todas as nuances da demanda da usuária. Note- 
se que, na linha 57, a usuária responde adicionando uma informação que se revela como crucial para a construção da compreensão entre as interagentes (sobre já ter tomado onze comprimidos, ao que a atendente demonstra novo entendimento, também confirmado pela usuária na linha 59). Observe-se agora o Excerto $\mathrm{A} 4{ }^{11}$ :

\section{Excerto A4}

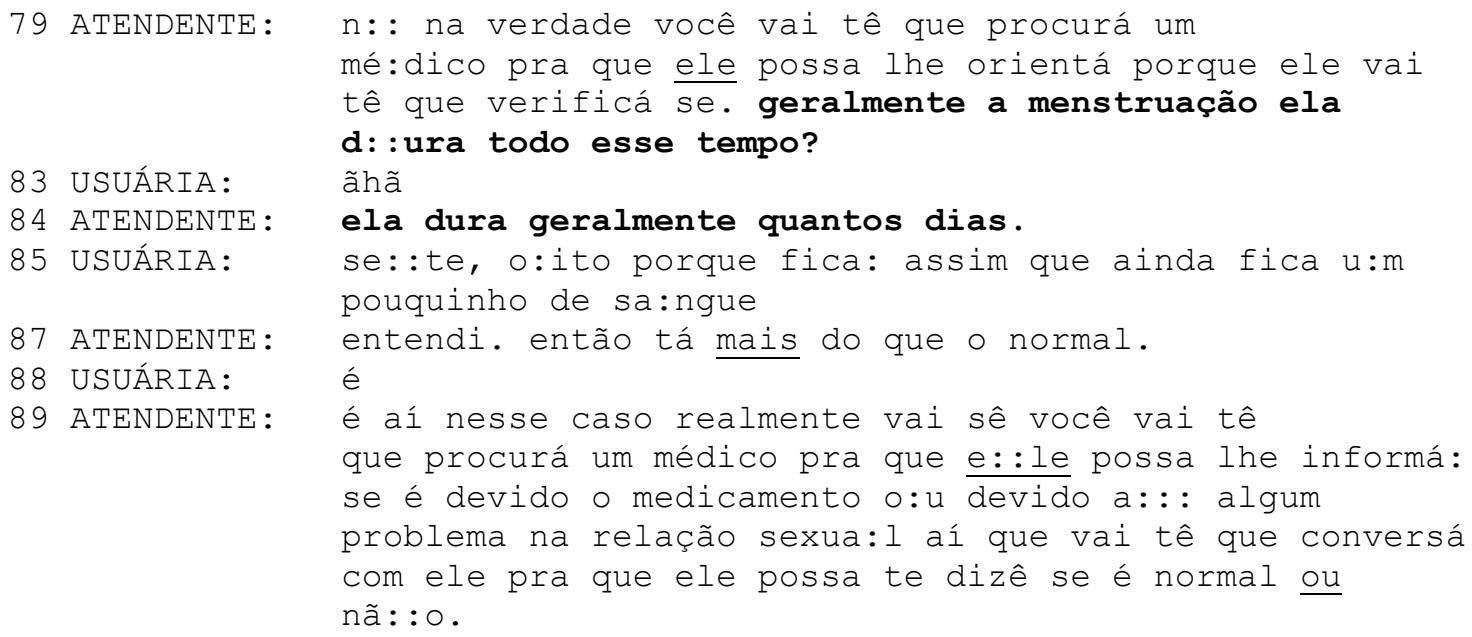

No Excerto A4, nas linhas 79 a 82, a atendente delineia uma orientação à atendente, mas interrompe a si mesma para fazer uma nova pergunta de afunilamento do assunto (se a menstruação geralmente dura todo esse tempo). $\mathrm{Na}$ linha 84 , a atendente reformula sua pergunta para uma mais específica. Na linha 85-86, a usuária responde com mais detalhes. Observe-se que na linha 87, a atendente parece sentir-se à vontade para dar seu parecer sobre o problema. Com as informações angariadas - por meio das suas perguntas de afunilamento -, e com as confirmações de seu entendimento a cada turno de fala - por meio de formulações -, a atendente produz seu entendimento final da situação: "então tá mais do que o normal", o que é confirmado pela usuária (linha 88). A partir da linha 89, a atendente orienta a usuária a buscar um médico que possa informar se sua situação está dentro da normalidade, sinalizando para a usuária a relevância da opinião médica em detrimento da opinião da própria atendente.

\subsection{PERGUNTAS QUE SE AFASTAM DA CONSTRUÇÃO DA COMPREENSÃO MÚTUA}

Nesta subseção, descrevem-se perguntas que, ao contrário das discutidas anteriormente, desviam-se da construção da compreensão mútua entre as participantes da conversa. Aqui a usuária inicia a interação tentando expressar à atendente sua dúvida nas linhas 1 a 3, reelaborando-a de forma mais direta nas linhas 7 e 8 . Salienta-se que essa ligação é realizada por outra usuária, atendida também por outra atendente.

\footnotetext{
${ }^{11}$ Por questões de espaço, alguns turnos são omitidos entre o final do excerto A3 e o início do A4 (linhas 60-78), em que mais perguntas são feitas à usuária.
} 


\section{Excerto B1}

1 USUÁRIA: eu queria sabê: porque quando a pessoa tá: : tá como é

o nome m desculpe (.) é co::m: : aids a pessoa tem

que:: :.h como se preveni ainda mais quando você tá

grávida

4 ATENDENTE: EU não entendi. você gostaria de saber o QUE sobre a AIDS?

(.)

7 USUÁRIA: Como se preveni para não transmitir a aids para o

seu bebê e porque eu estou grávida. e tenho aids.

Logo no começo da interação, a usuária engaja-se em uma tentativa de delinear a sua solicitação ao Disque Saúde, porém, como se nota nas linhas 1-3, com hesitação, o que sugere uma resistência em ter que tratar de um assunto supostamente delicado (SILVERMAN; PERÄKYLÄ, 1990), qual seja, AIDS. A hesitação fica perceptível pelos seus falsos inícios de palavras, pelas sílabas alongadas, pela breve pausa no meio da sua fala e pela inspiração (.h) na linha 2. No turno subsequente (linha 4), a atendente afirma não ter entendido, sinalizando um problema, ou seja, requerendo uma reapresentação do conteúdo expressado pela interlocutora naquela fala. A usuária, então, reformula sua solicitação sem hesitação no próximo turno (linhas 7-8), adicionando a informação de que está grávida e é portadora do vírus. Veja-se o Excerto B2:

\section{Excerto B2}

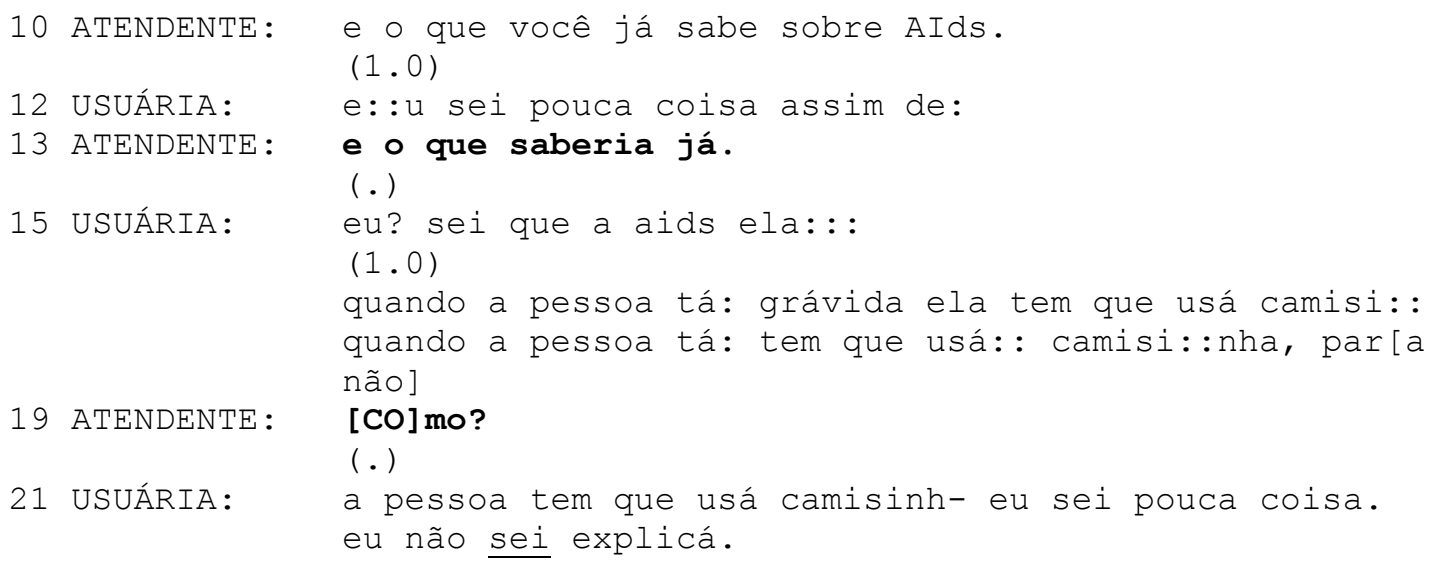

Na linha 10, a representante institucional dá início a uma sequência de pares de pergunta e resposta que fazem parte do par adjacente maior, o de solicitaçãoatendimento. Entretanto, a partir desse momento, as perguntas afastam-se da construção de uma compreensão mútua, contrapondo-se às perguntas de afunilamento analisadas na subseção anterior. Apenas a pergunta a respeito do que a usuária já sabe sobre a AIDS (linha 10) mostra-se relevante como afunilamento. Além disso, a abrupta sinalização de 
um problema pela atendente na linha 19 (“como?", dito simultaneamente à fala da usuária na linha anterior) demonstra a resistência da atendente em alinhar-se à situação delicada contida no relato da usuária ${ }^{12}$. Veja-se também o Excerto B3:

\section{Excerto B3}

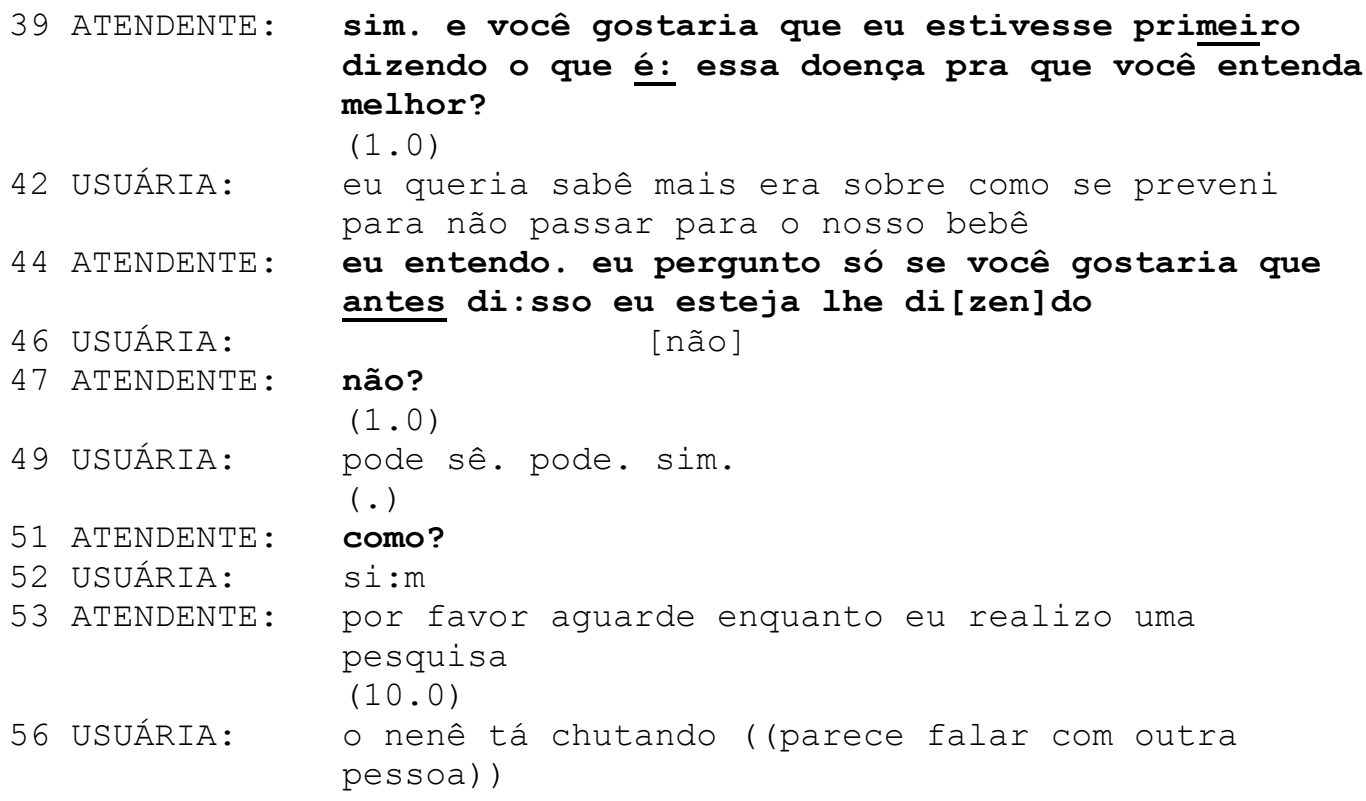

Nas linhas 39-40, a atendente oferece à usuária a informação sobre o que é a AIDS. A oferta é rejeitada pela usuária nas linhas 42-43: ela enfatiza e repete que sua solicitação é de informação sobre como fazer para não transmitir a doença para o filho que terá. Nota-se que, ao reiterar o que deseja saber, a usuária está fazendo um esclarecimento, movimento interacional que age para possibilitar o entendimento mútuo. Porém, há insistência da atendente na oferta (linhas 44-45), que angaria explícita rejeição da usuária em fala sobreposta (linha 46 - [não]). Aparentemente surpresa, a atendente devolve o "não" em entonação ascendente (linha 47), produzindo a sinalização de um problema que sugere que a usuária retroceda, cedendo à oferta - para ouvir uma explicação que não é a solicitada (linha 49). Assim, nas linhas 53-54, a atendente anuncia que irá pesquisar sobre o assunto, adiando ainda mais o atendimento à demanda inicial ${ }^{13}$ da usuária.

Além disso, observam-se nesse momento dois elementos na interação: primeiramente, a dificuldade da atendente em se descolar da orientação do script, que prevê que ela faça a "realização de uma pesquisa" trazendo à usuária informações sobre

\footnotetext{
${ }^{12}$ Entre o final do Excerto B2 e o início do Excerto B3, são omitidos alguns turnos da interação (linhas 23 a 38), nos quais a atendente questiona a usuária sobre onde ela ouviu sobre o HIV, ao que a usuária responde que fora em um posto de saúde de São Luis do Maranhão; qual o meio dessa informação, ao que ela responde que foi por meio de cartazes nesse posto; e também sobre o que estava escrito nesses cartazes, ao que a usuária lista três itens informativos.

${ }^{13}$ Aqui, diferentemente da interação da subseção anterior, a solicitação inicial é explicitamente proferida pela usuária por duas vezes (constando nos turnos de fala das linhas 7-8 e 42-43).
} 
a doença (correspondendo a um objetivo também pedagógico da instituição). E, em segundo lugar, a construção de uma assimetria pela atendente ao submeter a usuária a ouvir aquilo que ela não precisa ou não quer ouvir como uma "etapa" para conseguir ter sua real solicitação atendida depois. Veja-se o Excerto B4:

\section{Excerto B4}

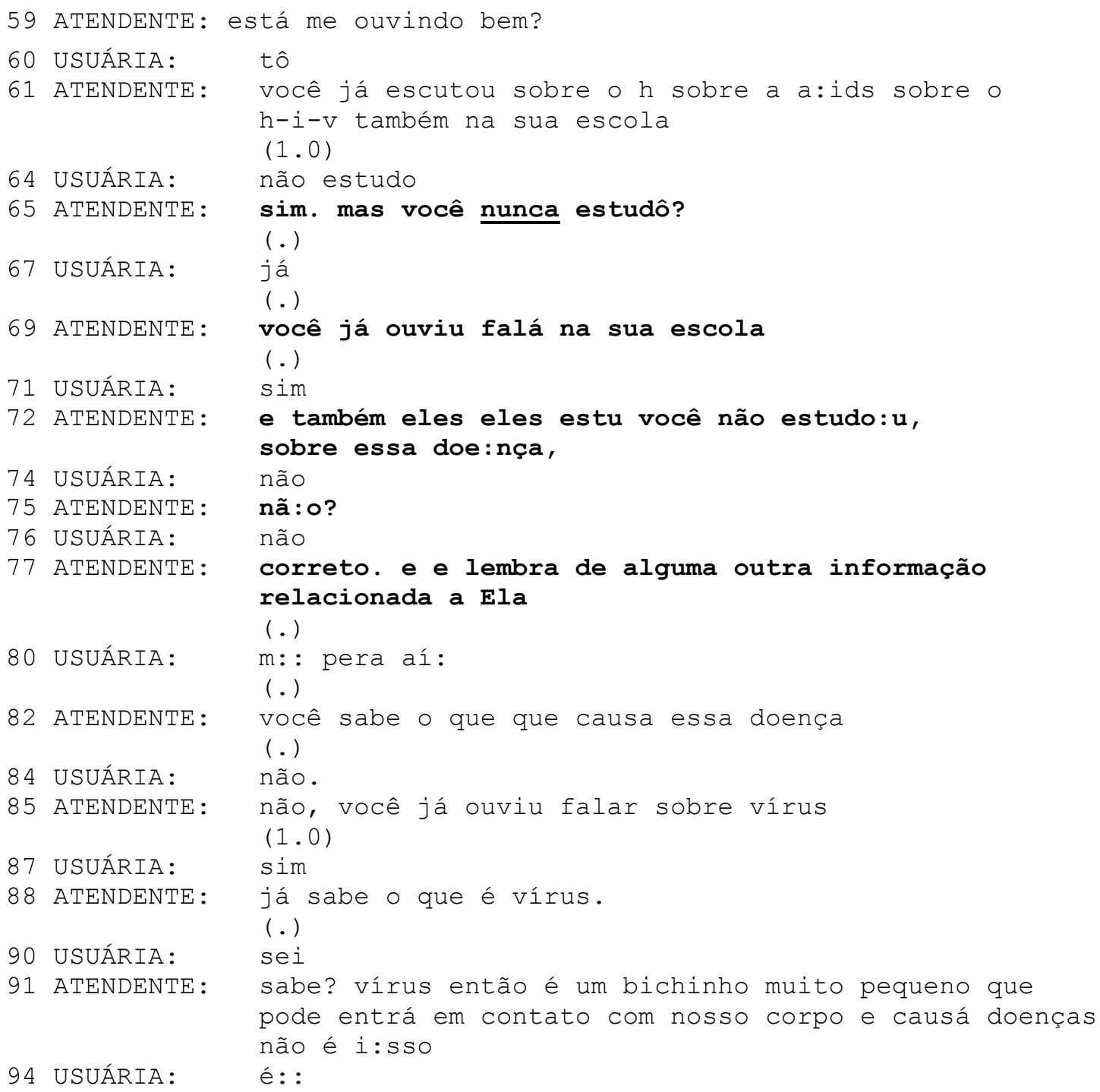

No Excerto B4, nas linhas 61-62, a atendente retorna à linha depois de seu momento de pesquisa com mais perguntas à usuária, em vez de respostas. Na linha 65 , ao perguntar "sim. mas você nunca estudô?", a atendente sinaliza um problema no conteúdo da fala da usuária. O mesmo acontece na linha 75. Observe-se o quanto essas sinalizações de problema acabam por constranger a usuária a falar o que a atendente quer ouvir. Além disso, a usuária torna-se monossilábica em seus turnos (linhas 67, 71, $74,76,84,87$ e 90), possivelmente pelo seu desconforto com o tratamento dado às suas contribuições pela atendente. Ela ainda tenta elaborar algo em sua fala na linha 80 ("m:: pera aí:"), o que parece ser ignorado pela atendente. 
As perguntas que sinalizam um problema (ou requerem uma reapresentação de conteúdo) no caso dessa ligação não estão a serviço da construção da compreensão mútua. As perguntas que a atendente produz nas linhas 65, 72-73 e 75 (sinalizações de problema) deixam transparecer sua surpresa sobre o fato de a usuária não frequentar uma escola e de não ter estudado sobre a doença especificamente. Essas informações são irrelevantes para a concretização do atendimento àquilo que a usuária solicitou e, assim, distanciam os participantes da possibilidade de atingirem um entendimento comum. Além disso, convoca-se o artigo sobre empatia na prática institucional (HEPBURN; POTTER, 2007) para dizer que a usuária poderia ter sido acolhida pelo serviço, haja vista o caráter delicado da sua situação.

Em outras palavras, pode-se afirmar que o script que os atendentes devem seguir consiste de etapas previstas para que a atendente venha a saber e compreender a demanda da usuária, ou seja, o assunto da ligação, e as perguntas por meio das quais ela fará isso são essenciais. Porém, em se tratando da característica da imprevisibilidade das interações, é sabido que a ordem apresentada no script não é a única em que uma interação naturalística pode ocorrer. Nem mesmo o conteúdo previsto pelo script é o único, pois, como já mencionado, as perguntas de sondagem, por exemplo, podem não se aplicar em determinada interação. Dessa forma, o uso do script, em vez de agir para calibrar os estados cognitivos tanto da atendente quanto da usuária, de maneira indiscriminada transforma a interação em um exercício de poder. Nessa situação, na qual a atendente faz perguntas às quais a usuária não consegue responder (por não serem legítimas para a construção da compreensão mútua), permanece a usuária em um estado constante de cognição insuficiente, e a atendente, como pessoa que domina o conhecimento e cujo papel é avaliar as contribuições da usuária.

Observa-se que a atendente atribui grande valor às regras de atendimento e, portanto, parece ficar presa a elas. Imagina-se que nos treinamentos ocorra $o$ encorajamento de um padrão no conteúdo de perguntas de sondagem (se a usuária já sabe alguma coisa sobre isso e onde ouviu falar disso $)^{14}$. Esse encorajamento, que possui provável fundamento na visão de comunicação como um conduto que leva uma mensagem pronta de A para B, transfere o foco da busca do entendimento e sondagem da solicitação para a realização de perguntas "scriptadas" de uma maneira indiscriminada. E essa realização do script consiste somente no cumprimento do que é prescrito, em detrimento da construção da compreensão mútua entre os interagentes.

\section{CONSIDERAÇÕES FINAIS: REFLEXÃO SOBRE AS PRÁTICAS DOS ATENDENTES DE UM SERVIÇO DE ATENDIMENTO TELEFÔNICO}

O presente artigo teve por objetivo fazer refletir sobre a construção da compreensão mútua como fator essencial nas interações, atrelada a características da aplicação das regras de atendimento no Disque Saúde. Para isso, foram apresentados dois exemplos de interações que tiveram diferentes desfechos, quais sejam: no primeiro

\footnotetext{
14 Imagina-se que os atendentes tenham tais exemplos no treinamento (ao que as pesquisadoras não tiveram acesso), porque é grande a quantidade de atendentes que utilizam essas duas perguntas (o que você já sabe sobre isso e onde ouviu falar disso) apesar de elas não estarem explicitadas no roteiro de atendimento.
} 
excerto observou-se a construção turno a turno do entendimento entre atendente e usuária do Disque Saúde; já no segundo houve problemas interacionais que impediram atendente e usuária de chegar a um entendimento mútuo. Assim, questiona-se o quanto a prescrição institucional para o atendimento do serviço estudado está centrada na "metáfora do conduto", por meio da indicação para que os atendentes realizem perguntas de sondagem e de confirmação a fim de compreender a necessidade da usuária. Nesse caso, tal prescrição torna-se contraproducente ao objetivo de atender o usuário com qualidade e de tratá-lo como uma pessoa única, entendendo suas reais necessidades.

Um encontro de serviço diádico carece de um mínimo de entendimento entre atendente e usuária. Além de atentar para essa premissa, a atendente precisa ainda orientar-se ao script em termos de perguntas de sondagem. Essa necessidade faz com que o esforço interacional aumente em uma interação que, de uma forma mais naturalística, ou seja, sem a obrigação dos scripts, poderia chegar mais facilmente à compreensão mútua. Pode-se conjecturar que a atendente encontra-se em um dilema diante de cada atendimento: ou ela segue o script da instituição que está embasado no entendimento da comunicação como "emissor-mensagem-receptor" (base da metáfora do conduto) e não privilegia a importância da sequencialidade na fala, ou ela faz um esforço interacional extra para dar conta das duas demandas: seguir o script e buscar entender a usuária até chegarem à mútua compreensão, o que é praticamente impossível por consistir em caminhos diferentes. Assim, o dilema em tela da atendente parece consistir em um trade-off (escolha de algo em detrimento de outro) entre o seguimento do script ou a via da compreensão mútua.

Os atendentes trabalham, então, constantemente sob esse dilema entre atender cada usuário como pessoa única, o que significa tratar cada interação como um caso singular, ou seguir os padrões, tal como colocado por Solomon et al. (1985). Os atendentes precisariam deixar de lado as prescrições em certos momentos para que conseguissem lidar com as outras instâncias de seu trabalho e concretizar o atendimento. Muitos atendentes o fazem, conseguindo realizar atendimentos que consideram primordialmente as demandas da usuária, para isso desprendendo-se de forma suficiente do que é prescrito. Sugere-se atenção da gestão de pessoas sobre esse aspecto, em que o atendente precisa ter clareza e habilidades que precisam ser desenvolvidas e/ou melhoradas em termos de flexibilidade para conseguir adaptar prescrição, a partir do script, na ação, nos momentos interacionais com os usuários.

Assim, chama a atenção o fato de as práticas exemplificadas serem tão diferentes entre si, e realizadas por profissionais que receberam o mesmo treinamento. Isso nos mostra o quanto, por mais que se tenham scripts e estratégias organizacionais, o trabalho está passível da subjetividade dos que o realizam e das diferentes interpretações de uma mesma prescrição e de uma mesma situação; por isso considera-se que a padronização e também a textualização excessivas são uma tentativa infrutífera de "controlar o incontrolável", nesse caso, a interação.

Essa característica do trabalho, principalmente do trabalho interacional, é o que corrobora a ideia de que a interação simplesmente não pode ser pensada pelo viés da "metáfora do conduto", tão largamente difundida em manuais de treinamento para atendimentos em call centers. A crença de que uma mensagem gramaticalmente correta e bem pronunciada sai do falante A e chega ao interlocutor B sendo ouvida exatamente 
conforme a intenção de A é um mito, já que essa linearidade não existe na prática dos encontros diádicos de serviço nem em qualquer conversa naturalística. $\mathrm{O}$ mais grave é que mesmo o entendimento de "texto" pela gestão do serviço em questão tem se mostrado de acordo com a metáfora do conduto. A comunicação interpessoal, como já demonstrado em uma infinidade de pesquisas de viés interacional, não opera como um conduto. Ela é coconstruída ao longo de uma conversa, um atendimento, não podendo estar pronta antes do evento em si. A interação é sempre única e específica, e precisa ser pensada e tratada como tal pelas organizações.

A sugestão para o serviço estudado envolve uma reflexão que deve anteceder à reformulação dos scripts de atendimento: a própria compreensão dos mecanismos da comunicação humana, levando em consideração a sequencialidade da fala e a sua imprevisibilidade, o que vai além da percepção de comunicação como na metáfora do conduto. Para isso, os esforços descritos nas práticas de formulações e de perguntas de afunilamento parecem fazer com que o encontro de serviço diádico tenha sucesso no intento de atender à demanda de fornecer as informações solicitadas pela usuária e orientá-la adequadamente, conforme visto na Interação A. Sabe-se que a maioria das organizações está longe desse entendimento e que, caso houvesse essa conscientização, para a sua aplicação seria necessária grande ênfase no treinamento e em momentos de avaliação, bem como uma mudança substancial no roteiro de atendimento.

Ainda, uma importante reflexão que perpassa este estudo é a consequência da padronização da fala dos atendentes, conforme também observaram Silva et al (2002). Seus efeitos comprometem a "natureza dialógica do discurso, a relevância das condições situadas de sua ocorrência e a coerência do texto conversacional" (p. 4). Nas interações do Disque Saúde, sem dúvida, o que fica mais evidente como resultado desse controle sobre a fala é justamente a falta de empatia e de acolhimento (cujas evidências estão sempre na linguagem) com a usuária do serviço, o que não vai ao encontro dos propósitos de humanização dos atendimentos mencionados pela Política de Humanização do SUS. Ao mesmo tempo, os ensinamentos do livro Como encantar o cliente pelo telefone, no qual a gestão dessa instituição diz se basear para planejar seu treinamento, parecem ter influenciado pouco os atendentes nas suas práticas discursivas.

Este artigo quer fazer refletir também sobre o papel da gestão de pessoas nas organizações, sejam públicas ou privadas, chamando atenção para o que pode ser visto e, por consequência, realizado, ao se voltar o olhar para a linguagem de uma forma mais detida. Questiona-se aqui a importância dada a fatores macroestruturais como definição de modelos de gestão e de políticas de atuação em detrimento da atenção situada na atividade de trabalho em si, na maneira pela qual a atividade se constitui na prática, com suas especificidades atreladas aos sujeitos de determinada interação e às suas ações.

\section{REFERÊNCIAS}

ANDERSON, K. Como encantar o cliente pelo telefone. Rio de Janeiro: Campus, 1995.

BAKER, C.; EMMISON, M.; FIRTH, A. Calling for help: language and social interaction in telephone helplines. Amsterdam: John Benjamins Publishing Company, 2005. 
BORGES, M. L.; OSTERMANN, A. C. "Quem vai definir isso aí é tu”: a fala-em-interação em contextos de decisões empresariais de emergência. ReVEL, v. 11, n. 21, p. 117-139, 2013.

CLIFTON, J. A discursive approach to leadership: doing assessments and managing organizational meanings. Journal of Business Communication, v. 49, n. 2, p.148-168, 2012.

2009.

Beyond taxonomies of influence. Journal of Business Communication, v. 46, n. 1, p. 57-79,

DREW, P.; HERITAGE, J. Talk at work: interaction in institutional settings. Cambridge: Cambridge University Press, 1992.

HEPBURN, A.; POTTER, J. Crying receipts: time, empathy, and institutional practice. Research on Language and Social Interaction, v. 40, n. 1, p. 89-116, 2007.

HUTCHBY, I.; WOOFFITT, R. Conversation analysis: principles, practices and applications. Cambridge: Polity Press, 1998. 273p.

JUNG LAU, C. R.; OSTERMANN, A. C. As interações no telemarketing ativo de cartões de crédito: da oferta velada à rejeição. Alfa: Revista de Linguística, São Paulo, v. 49, n. 2, p. 65-88, 2005.

LLEWELLYN, N.; HINDMARSH, J. Work and organisation in real time: an introduction. In: Organisation, interaction and practice: studies in ethnomethodology and conversation analysis. Cambridge: Cambridge University Press, 2010.

MA, Z.; DUBÉ, L. Process and outcome interdependency in frontline service encounters. Journal of Marketing, v. 75, n. 3, p. 83-98, 2011.

OLIVEIRA, M. do C. L. de. Linguística aplicada a contextos empresariais: uma entrevista com Maria do Carmo Leite de Oliveira. ReVEL, v. 11, n. 21, 2013.

Por uma linguística aplicada mais inclusiva. Calidoscópio, São Leopoldo, v. 7, n. 2, p. 93-96, maio/ago. 2009.

OSTERMANN, A. C. Análise da Conversa: o estudo da fala-em-interação. In: OSTERMANN, A. C.; MENEGHEL, S. N. Humanização. Gênero. Poder: contribuições dos estudos de fala-em-interação para a atenção à saúde. Rio de Janeiro/São Paulo: Fiocruz e Mercado de Letras, 2012.

OSTERMANN, A. C.; ANDRADE, D. N. P.; SILVA, J. Análise da Conversa Aplicada em interações entre médicos e pacientes. Veredas, Juiz de Fora, n. 2, p. 114-135, 2013.

OSTERMANN, A. C.; SILVA, C. A formulação em consultas médicas: para além da compreensão mútua entre os interagentes. Calidoscópio, v. 7, n. 2, p. 97-111, 2009.

OSTERMANN, A. C.; SOUZA, J. de. As demandas interacionais das ligações para o Disque Saúde e sua relação com o trabalho prescrito. Alfa: Revista de Linguística, v. 55, n. 1, p. 135-162, 2011.

REDDY, M. A metáfora do conduto: um caso de conflito de enquadramento na nossa linguagem sobre a linguagem. Tradução de Ilesca Holsbach, Fabiano Gonçalves, Marcela Migliavacca e Pedro Garcez. Cadernos de Tradução, Porto Alegre, n. 9, p. 5-47, jan./mar. 2000 [1979].

SACKS, H.; SCHEGLOFF, E.; JEFFERSON, G. The simplest systematics for turn-taking in conversation. Language, v. 50, n. 4, p. 696-735, 1974.

SAMRA-FREDERICKS, D. Ethnomethodology and the moral accountability of interaction: navigating the conceptual terrain of "face" and face-work. Journal of Pragmatics, v. 42, p. 2147-2157, 2010.

SILVA, J. R. G. et al. Operadores de call center: inconsistências e desafios para a gestão de pessoas. Banco de papers. In: ENANPAD - Encontro Nacional dos Programas de Pós-Graduação em Administração, 26., Salvador, 2002.

SILVERMAN, D.; PERÄKYLÄ, A. AIDS counselling: the interactional organisation of talk about "delicate" issues. Sociology of Health \& Illness, v. 12, n. 3, p. 293-318, 1990.

SOLOMON, M. R. et al. A role theory perspective on dyadic interactions: the service encounter. Journal of Marketing, n. 49 (Winter), p. 99-111, 1985.

WEICK, Karl E. Sensemaking in organizations. Thousand Oaks: SAGE, 1995.

ZIMMERMAN, D. H. Talk and its occasion: the case of calling the police. In: SCHIFFRIN, Deborah (Ed). Meaning, form, and use in context: linguistic applications. Washington: Georgetown University Press, 1984. p. 210-228. 
Recebido em: 08/04/14. Aprovado em: 19/10/14.

Title: Controling the uncontrolable: the application of attendance rules in the construction of mutual comprehension between client and attendants in a Call Center

Authors: Joseane de Souza; Ana Cristina Ostermann; Maria de Lourdes Borges

Abstract: This article aims to analyze mutual understanding as an aspect of dyadic behaviors in a service encounter, since it is a little-explored discursive element as the literature on Marketing and People Management shows (MA; DUBÉ, 2011). Specifically, we investigate how mutual understanding may or may not be constructed between callers and call-takers of a helpline in accordance to the guidelines (textual element) made by People Management that call-takers must follow in the process. We use the Conversation Analysis approach (SACKS; SCHEGLOFF; JEFFERSON, 1974) to analyze naturallyoccurring interactions in a micro ethnographic way. The data comprise 126 audiorecorded interactions from Disque Saúde call center in Brasilia. The results reveal that simply following the guidelines does not guarantee the construction of mutual understanding and, on the contrary, leaves room for distinct social actions, like abandoning mutual comprehension when call-takers face interactional demands that cannot be predicted by a script.

Keywords: Conversation Analysis. Helplines. Telephone interactions. Guidelines. Humanization.

Título: Controlar lo incontrolable: la aplicación de las reglas de atendimiento en la construcción de la comprensión mutua entre clientes y asistentes en un Call Center

Autores: Joseane de Souza; Ana Cristina Ostermann; Maria de Lourdes Borges

Resumen: Este artículo propone analizar la comprensión mutua como una faceta de los comportamientos diádicos en un encuentro de servicio, elemento discursivo poco estudiado, conforme la literatura de marketing y gestión de personas apunta (MA; DUBÉ, 2011). Especificamente, se investiga cómo la comprensión mutua es o no es construida entre clientes y asistentes de un servicio telefónico desde la aplicación de los scripts y reglas de atendimiento (elemento textual) criadas por la gestión de personas. Utilizando el Análisis de la Conversación (SACKS; SCHEGLOFF; JEFFERSON, 1974), se analizan datos reales de interacciones de manera micro-etnográfica. El corpus de este artículo es constituido de 126 interacciones gravadas en audio en el centro de llamadas Disque Saúde en Brasília. Los resultados revelan que sólo el seguimiento de las reglas no garantiza el estabelecimiento de la comprensión mutua, al contrario, deja margen para interacciones distintas, como el abandono de la comprensión mutua cuando los asistentes se deparan con demandas en la interacción que no pueden ser previstas por el script.

Palabras-clave: Análisis de la Conversación. Helplines. Interacción al teléfono. Prescripciones. Humanización. 